\title{
Anstelle einer Zusammenfassung
}

Mit diesem Buch möchten die Autoren Sie dabei unterstützen, Ihre ersten Schritte mit der sinnvollen Verbindung von Objectives and Key Results und LEGO ${ }^{\circledR}$ SERIOUS PLAY ${ }^{\circledR}$ zu unternehmen. Warum?

Weil wir glauben, dass Objectives and Key Results einen unmissverständlichen Fokus für einen überschaubaren Zeitraum schaffen und die Brücke von der Unternehmensvision zu den notwendigen Aktivitäten schlagen.

Weil wir glauben, dass LEGO ${ }^{\circledR}$ SERIOUS PLAY ${ }^{\circledR}$ bisher eher verschwommene Themen endlich greifbar macht und enorm dabei hilft, den eigenen Standpunkt auszudrücken und sich und andere besser zu verstehen.

Weil wir glauben, dass die intelligente Verbindung dieser Ansätze dabei unterstützt, ihre Ziele und die damit verbundenen Fragen und Antworten auf den Tisch zu bringen und eine gemeinsame Sicht zu schaffen.

Es gibt dabei kein Falsch und Richtig. Nur ein Hilfreich. Verwenden Sie das, was Ihnen nützt, modifizieren Sie das, was Ihnen noch nicht passend erscheint, und legen Sie los. „Leg godt!“, spielen Sie gut! 